\title{
Anatomical features associated with venous congestion in DIEP flap using CT angiography with three-dimensional reconstruction
}

\author{
Alejandro Ruiz-Moya1, Rafael-Antonio Lopez-Garcia', Domingo Sicilia-Castro', Tomas Gomez-Cia', \\ Pedro Infante-Cossio ${ }^{2}$ \\ ${ }^{1}$ Department of Plastic and Reconstructive Surgery, Virgen del Rocio University Hospital, 41013 Seville, Spain. \\ ${ }^{2}$ Department of Surgery, School of Medicine, University of Seville, 41009 Seville, Spain.
}

Correspondence to: Dr. Pedro Infante-Cossio, Department of Surgery, School of Medicine, University of Seville, Av. Dr. Fedriani, 41009 Seville, Spain. E-mail: pinfante@us.es

How to cite this article: Ruiz-Moya A, Lopez-Garcia RA, Sicilia-Castro D, Gomez-Cia T, Infante-Cossio P. Anatomical features associated with venous congestion in DIEP flap using CT angiography with three-dimensional reconstruction. Plast Aesthet Res 2017;4:127-34.

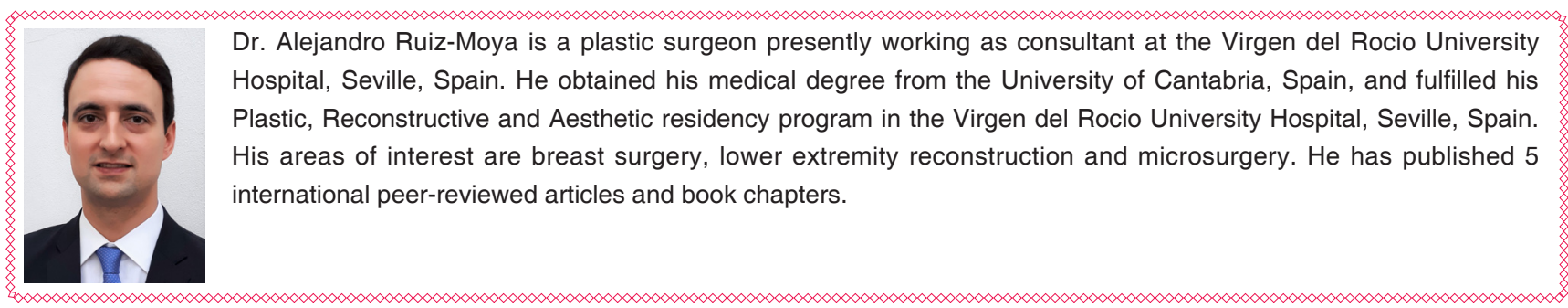

Article history:

Received: 12-04-2017

Accepted: 20-07-2017

Published: 21-08-2017

Key words:

Deep inferior epigastric artery

perforator,

flap,

venous congestion,

breast reconstruction,

computed tomography

angiography,

preoperative imaging,

virtual reality

\begin{abstract}
Aim: Computed tomography angiography (CTA) using three-dimensional (3D) virtual reconstruction has been increasingly used in planning deep inferior epigastric artery perforator (DIEP) breast reconstruction. Although the most common complication associated with this surgery is diffuse venous congestion, its origin remains unclear. The aim of this study was to assess the anatomical characteristics of the anterior abdominal wall vessels that could predict venous congestion, using CTA with 3D virtual reconstruction. Methods: A retrospective case-control study was conducted and a total of 169 DIEP flaps were reviewed. An abdominal CTA with $3 \mathrm{D}$ virtual reconstruction was analyzed with regard to anatomical features of the abdominal wall vessels. Seven venous congestive cases were identified. For each case, 3 controls that had not exhibited any vascular complications were randomly selected. Results: The global venous congestion rate was $4.14 \%$. No statistically significant differences were found between the groups' superficial inferior epigastric vein (SIEV) diameter $(P=0.915)$, number of branches of SIEV $(P=0.371)$, number of perforators per flap $(P=0.255)$, flap subcutaneous tissue thickness $(P=0.652)$, direct communications between SIEV-perforators $(P=0.418)$, and communications of both SIEVs across the abdominal midline $(P=0.371)$. Conclusion: The present study provided
\end{abstract}

(7) (2) This is an open access article distributed under the terms of the Creative Commons AttributionNonCommercial-ShareAlike 3.0 License, which allows others to remix, tweak, and build upon the work non-commercially, as long as the author is credited and the new creations are licensed under the identical terms.

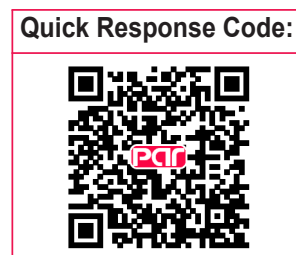


new information concerning the identification of the controversial anatomical features associated with venous congestion in DIEP flaps. CTA and 3D virtual reconstruction were useful tools for evaluating the abdominal wall anatomy and for planning DIEP breast surgery, but neither for predicting nor preventing the diffuse congestive phenomenon.

\section{INTRODUCTION}

Since the deep inferior epigastric artery perforator (DIEP) flap was used for the first time for breast reconstruction by Allen and Treece, ${ }^{[1]}$ it has been adopted as the gold standard for autologous breast reconstruction, overtaking other popular autologous methods such as the latissimus dorsi flap and the transverse rectus abdominis myocutaneous flap. The amount of available tissue, the low abdominal morbidity, the ability of replacing like-for-like, and the good aesthetic results, are the most notable advantages of this technique that have contributed to its widespread use. ${ }^{[2]}$ The success rate is high, with a flap loss rate under $3 \%$ according to the review by Lie et all. ${ }^{[3]}$ on more than 17,000 DIEP flaps.

The main arterial inflow is provided by the deep inferior epigastric artery (DIEA), while the main venous drainage is provided by the superficial inferior epigastric vein (SIEV). Although the arterial component of the flap has been widely documented,${ }^{[4,5]}$ the venous system has not been as thoroughly studied. When a DIEP flap is dissected, a redirection of the venous oufflow occurs from the dominant superficial system to the deep system. This redistribution could favor venous congestion in some of the flaps, leading to the most common vascular complication, the diffuse venous congestion of the DIEP flap, neither caused by pedicle-related issues (such as venous thrombosis or kinking) nor by technical errors (for example, deficient suture or avulsion of the pedicle). ${ }^{[6,7]}$ This phenomenon is observed in $2-10.9 \%$ of cases ${ }^{[7-9]}$ and it may cause partial or total flap loss if unsolved. In fact, up to $40 \%$ of total DIEP flap necrosis are associated with venous problems. ${ }^{[3]}$ Paradoxically, the mechanisms behind this complication remain unclear and have not been clarified yet.

Several strategies exist to overcome such complication of DIEP flap diffuse venous congestion. . $^{[1-12]}$ However, the origin remains to be elucidated. Some triggering factors have been proposed: diameter of the SIEV larger than $1.5 \mathrm{~mm},{ }^{[6,13]}$ absence of communications of both SIEVs crossing the abdominal midline, ${ }^{[6,13]}$ absence of direct communications by perforators between the SIEV and the deep inferior epigastric vein $(\mathrm{DIEV}),{ }^{[6]}$ number of perforators of the flap, ${ }^{\left[{ }^{[}\right]}$ and subcutaneous tissue thickness. ${ }^{[14]}$ Nevertheless, scarce evidence has been reported to date as only one study was able to refuse the correlation with the diameter of the SIEV ${ }^{[8]}$ and another one indicated a higher chance of congestion in DIEP flaps based on just one perforator without direct communication with the SIEV.[]

The routine use of preoperative imaging to assess the microvascular anatomy of the anterior abdominal wall helps to achieve optimal outcomes. ${ }^{[15]}$ Preoperative planning of DIEP flaps with computed tomographic angiography (CTA) followed by three-dimensional (3D) reconstruction has proved to be an effective technique to map the abdominal vascular anatomy, allowing a better tracking of the perforators, including their size, location and course, so as to shorten the operative time and number of complications ${ }^{\left[{ }^{[1,17]}\right.}$ On the other hand, little is known about the anatomical features related with the postoperative diffuse venous congestion and how new imaging technologies are able to identify aspects that can threaten the perfusion of the DIEP flap.

This study aimed to evaluate the anatomical features that could preoperatively predict the potential venous congestion of DIEP flaps, using $3 \mathrm{D}$ virtual reconstructions from CTA.

\section{METHODS}

This retrospective case-control study included 210 consecutive DIEP breast reconstructions in which a CTA was performed prior to surgery. These flaps were carried out consecutively by the same surgeon (D. Sicilia-Castro) in the Department of Plastic and Reconstructive Surgery of the Virgen del Rocio University Hospital in Seville, Spain, between January 2004 and January 2016. All patients were prophylactically administered low molecular weight heparin every $24 \mathrm{~h}$ postoperatively, in a dose of $40 \mathrm{mg}$ of enoxaparin, and flaps were assessed clinically and with a hand-held Doppler probe hourly during the first $48 \mathrm{~h}$, and every $2 \mathrm{~h}$ during the next $48 \mathrm{~h}$. All patients signed informed consent to be included in the study.

Cases were defined as DIEP flaps preoperatively planned with CTA and $3 \mathrm{D}$ virtual reconstruction, which exhibited diffuse venous congestion intraoperatively after ligating the SIEV, not due to pedicle-related issues (venous thrombosis, twisting or kinking) or to technical failures (deficient suture or venous avulsion during manipulation). Controls were defined as DIEP flaps preoperatively planned with CTA and $3 \mathrm{D}$ virtual 
reconstruction, that did not exhibit previous nor other vascular complication, such as arteriovenous thrombosis or necrosis.

Thirty-seven reconstructions were excluded as the preoperative perforator mapping was performed with a hand-held Doppler probe. Four flaps that had exhibited vascular complications different to diffuse venous congestion ( 2 cases of intraoperative partial venous congestion related to abdominal midline scars, 1 case of intraoperative venous thrombosis, and 1 case of late venous thrombosis 6 days following the surgery) were discarded as well. The final sample group included data from 169 DIEP flaps. According to the inclusion criteria, 7 cases were identified as diffuse congestive flaps [Figure 1]. Due to the limited number of cases, 3 controls per case (21 controls) were selected by computer randomization, in an attempt to control the power of the study and to avoid selection bias.

\section{Imaging procedures}

The studies of CTA were carried out by a 16 -detectorrow computed tomography scanner (General Electric Light-Speed 16; General Electric Company, Fairfield, Conn.). The parameters followed by the CT scans were: $0.37 \mathrm{~s}$ rotational speed of the gantry, $0.63 \mathrm{~mm}$ collimator width slice thickness, and 1.37 helical detector pitch. The voltage of the X-ray tube was $120 \mathrm{kV}$ and tube current was 250 to $300 \mathrm{~mA}$. Prior to scanning, all patients received an intravenous administration of $100 \mathrm{~mL}$ of nonionic iodinated contrast medium at a concentration of $350 \mathrm{mg} / \mathrm{mL}$ (Omnipaque 350; GE Healthcare, Barcelona, Spain) into an antecubital vein.

Sections of 0.63 in width were obtained at an $0.5-\mathrm{mm}$ interval from $4 \mathrm{~cm}$ above the umbilicus to the minor trochanter of the hip. The resulting set of images was automatically transferred to a computer workstation, which generated multiplanar reformatted images and $3 \mathrm{D}$ volume-rendered images. Data were stored as a Digital Imaging and Communications in Medicine (DICOM) compatible file on a CD-ROM to be uploaded to a personal computer with the AYRA $^{\circledR}$ software (formerly known as VirSSPA ${ }^{\circledR}$; Andalusian Health Department, Seville, Spain). The 3D reconstructions of the abdominal wall were generated using the DICOM files by means of the virtual reality AYRA $^{\circledR}$ software. All the variables were assessed in these $3 \mathrm{D}$ virtual models.

\section{Evaluation of the images}

The preoperative 3D reconstruction of each case was retrieved by the same observer (A. RuizMoya). The following anatomical variables were retrospectively analyzed in both groups: the existence of direct communications between the SIEV and the perforators of the flap [Figure 2], the existence of communications of both SIEVs across the abdominal midline [Figure 3], the 8-cm-diameter SIEV caudal to the most superior aspect of the iliac crests [Figure 4], the number of branches of the SIEV, the number of perforators included in each flap [Figure 5], and the flap subcutaneous tissue thickness at a point located

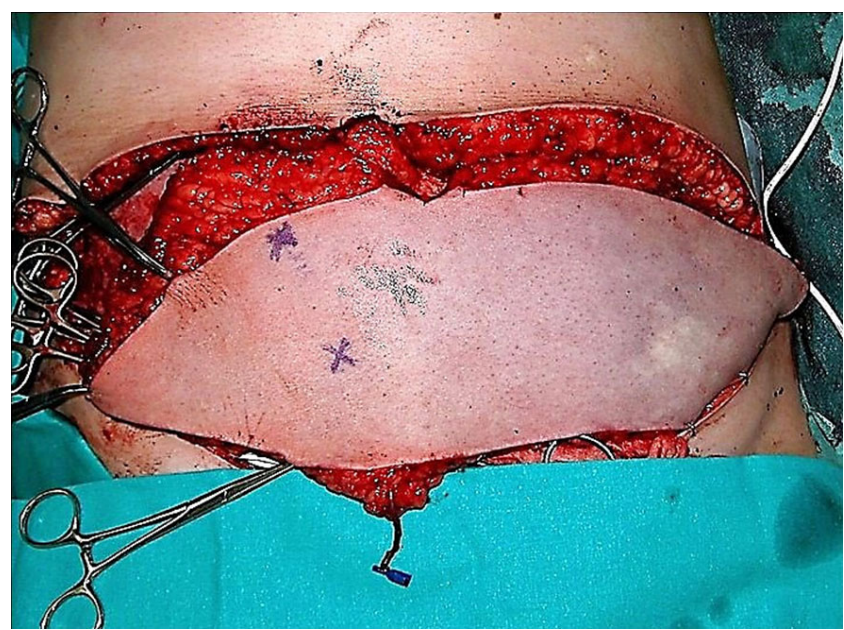

Figure 1: Deep inferior epigastric artery perforator flap exhibiting diffuse venous congestion

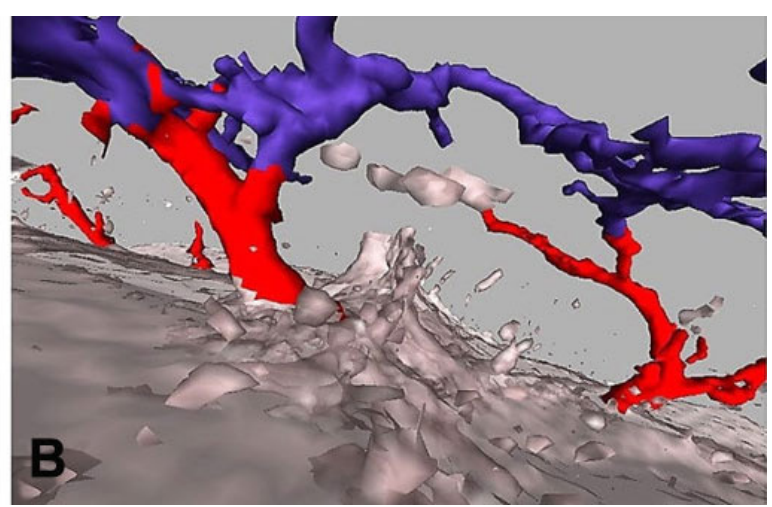

Figure 2: Three-dimensional abdominal wall reconstruction with AYRA software from computed tomography angiography images. (A) Point of assessment (circle) of direct communications between perforators (red) and superficial venous system (blue); (B) direct communications viewed from the abdominal wall 
at the level of the most superior aspect of the iliac crests and at the midpoint of the rectus abdominis muscle width [Figure 6].

\section{Statistical analysis}

According to the small sample size, the quantitative variables were evaluated with the U-Mann-Whitney non-parametric test, and the qualitative variables with the Fisher exact test. For the statistical analysis, the IBM SPSS Statistics 19 package ${ }^{\circledR}$ (SPSS Inc. Chicago, IL) was used, considering significant differences when $P<0.05$.

\section{RESULTS}

The global venous congestion rate was $4.14 \%$ ( 7 flaps). The mean age of case and control subjects was 50.1 years (range 38-58 years) and 49.1 years (range 35-64 years), respectively.

In the case group, direct communications between the DIEA and the SIEV through perforators were found in $57.14 \%$ of flaps (4 cases), direct communications

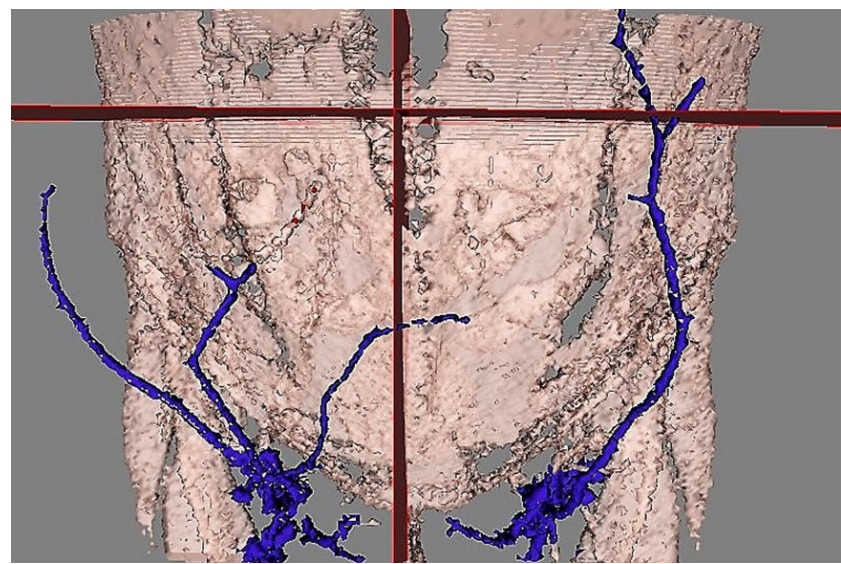

Figure 3: Three-dimensional abdominal wall reconstruction with AYRA software from computed tomography angiography images showing direct venous communication of the superficial inferior epigastric vein across the abdominal midline

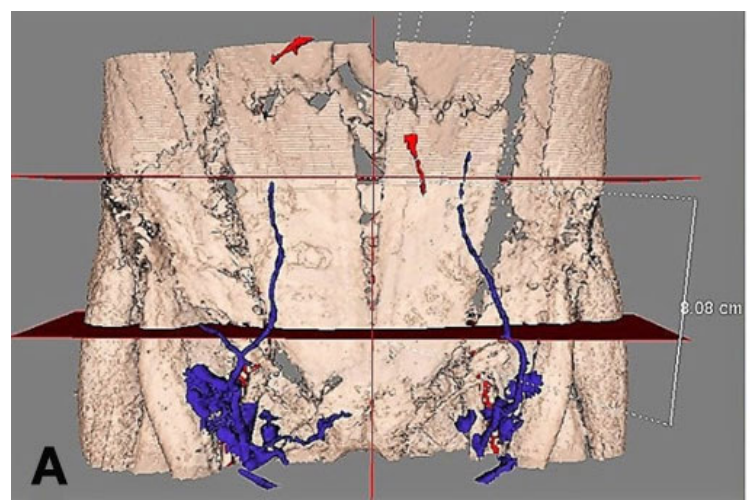

of both SIEVs across the abdominal midline were found in $42.86 \%$ of flaps (3 cases), with a mean diameter of the SIEV of $3.04 \mathrm{~mm}( \pm 0.60 \mathrm{~mm})$, a mean of 1.43 branches per SIEV, a mean of 1.86 ( \pm 0.69) perforators nourishing each flap, and with an average flap subcutaneous tissue thickness of 3.56 $\mathrm{cm}( \pm 0.90 \mathrm{~cm})$ [Table 1]. In every congestive flap, an additional venous anastomosis was performed, either to the second concomitant vein of the DIEA (5 cases) or to the cephalic vein (2 cases). After this salvage procedure, all of the 7 flaps overcame congestion and survived without necrosis. In the control group, direct communications between the DIEA and the SIEV through perforators were found in $38.10 \%$ of flaps (8 controls), direct communications of both SIEVs across the abdominal midline were found in $23.81 \%$ of flaps ( 5 controls), with a mean diameter of the SIEV of 3.08 $\mathrm{mm}( \pm 1.20 \mathrm{~mm})$, a mean of 1.24 branches per SIEV, a mean of 2.24 ( \pm 0.77 ) perforators nourishing each flap, and with a mean flap subcutaneous tissue thickness of $3.72 \mathrm{~cm}( \pm 0.83 \mathrm{~cm})$ [Table 2]. No statistically significant differences were found between the two groups for any of the variables $(P>0.05)$ [Table 3$]$.

\section{DISCUSSION}

The present study was not able to confirm any of the studied anatomical variables as predictive factors of venous congestion, despite being suggested in the literature. ${ }^{[5,6,13,14]}$ The abdominal superficial venous dominance is one of the most extended and accepted (but not proved) hypothesis for explaining the diffuse congestion as a large diameter SIEV may denote dominance over the deep venous system. ${ }^{[6]}$ Blondeel et al ${ }^{[13]}$ suggested that when this diameter is $>1.5 \mathrm{~mm}$, the SIEV should be preserved for venous supercharging in case of congestion. However, in a study with CT angiography, Sadik et al. ${ }^{[8]}$ did not find a correlation between the SIEV diameter and the venous dominance of the flap, concluding that the SIEV

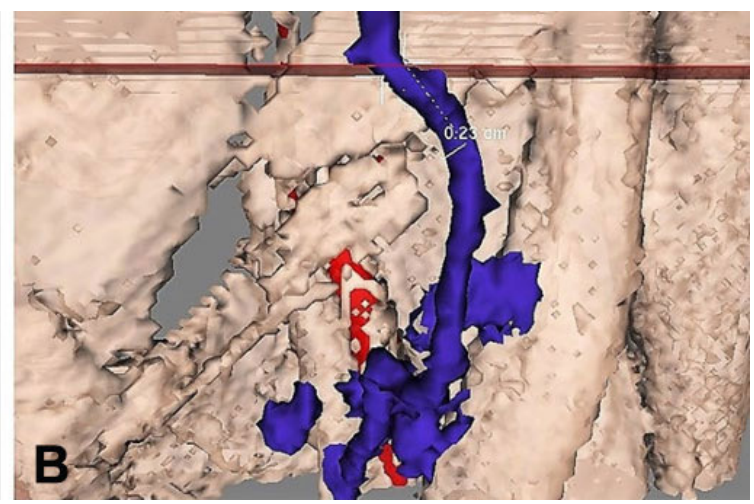

Figure 4: Three-dimensional abdominal wall reconstruction with AYRA software from computed tomography angiography images. (A) Horizontal plane $8 \mathrm{~cm}$ inferior to the horizontal plane connecting the iliac crests, marking level of measurement of the SIEV diameter; (B) measurement of the SIEV diameter. SIEV: superficial inferior epigastric vein 
Table 1: Variables studied in case group

\begin{tabular}{|c|c|c|c|c|c|c|c|}
\hline $\begin{array}{l}\text { Case } \\
\text { No. }\end{array}$ & $\begin{array}{l}\text { Communication } \\
\text { SIEV DIEA }\end{array}$ & $\begin{array}{c}\text { Communication } \\
\text { SIEV }\end{array}$ & $\begin{array}{l}\text { Diameter of } \\
\text { SIEV }(\mathbf{m m})\end{array}$ & $\begin{array}{c}\text { Branches of } \\
\text { SIEV }\end{array}$ & Perforators & $\begin{array}{l}\text { Subcutaneous } \\
\text { thickness (cm) }\end{array}$ & $\begin{array}{c}\text { Age } \\
\text { (years) }\end{array}$ \\
\hline 1 & No & No & 2.7 & 2 & 3 & 2.38 & 51 \\
\hline 2 & Yes & Yes & 3.6 & 2 & 2 & 3.19 & 48 \\
\hline 3 & Yes & Yes & 2.4 & 1 & 2 & 2.91 & 49 \\
\hline 4 & No & No & 2.9 & 1 & 2 & 4.49 & 38 \\
\hline 5 & Yes & No & 3.9 & 1 & 2 & 2.98 & 54 \\
\hline 6 & Yes & Yes & 3.5 & 2 & 1 & 4.35 & 53 \\
\hline 7 & No & No & 2.3 & 1 & 1 & 4.64 & 58 \\
\hline
\end{tabular}

SIEV: superficial inferior epigastric vein; DIEA: deep inferior epigastric artery

Table 2: Variables studied in control group

\begin{tabular}{|c|c|c|c|c|c|c|c|}
\hline $\begin{array}{l}\text { Case } \\
\text { No. }\end{array}$ & $\begin{array}{l}\text { Communication } \\
\text { SIEV DIEA }\end{array}$ & $\begin{array}{c}\text { Communication } \\
\text { SIEV }\end{array}$ & $\begin{array}{l}\text { Diameter of } \\
\text { SIEV }(\mathrm{mm})\end{array}$ & $\begin{array}{l}\text { Branches of } \\
\text { SIEV }\end{array}$ & Perforators & $\begin{array}{l}\text { Subcutaneous } \\
\text { thickness }(\mathrm{cm})\end{array}$ & $\begin{array}{c}\text { Age } \\
\text { (years) }\end{array}$ \\
\hline 1 & Yes & No & 3.4 & 1 & 3 & 3.98 & 58 \\
\hline 2 & No & No & 3.0 & 1 & 3 & 2.72 & 54 \\
\hline 3 & No & No & 3.7 & 2 & 2 & 5.00 & 39 \\
\hline 4 & Yes & No & 2.7 & 1 & 2 & 4.14 & 57 \\
\hline 5 & No & No & 4.5 & 1 & 3 & 4.66 & 41 \\
\hline 6 & No & No & 1.7 & 1 & 2 & 3.70 & 64 \\
\hline 7 & Yes & No & 2.6 & 1 & 3 & 2.69 & 51 \\
\hline 8 & No & No & 3.1 & 1 & 2 & 4.50 & 35 \\
\hline 9 & No & No & 2.1 & 1 & 3 & 3.27 & 40 \\
\hline 10 & No & Yes & 2.4 & 2 & 2 & 3.50 & 50 \\
\hline 11 & Yes & Yes & 3.5 & 1 & 2 & 3.70 & 51 \\
\hline 12 & Yes & No & 3.6 & 2 & 2 & 4.42 & 47 \\
\hline 13 & No & No & 3.1 & 1 & 2 & 3.70 & 57 \\
\hline 14 & Yes & No & 3.3 & 2 & 1 & 4.27 & 50 \\
\hline 15 & No & No & 2.7 & 1 & 4 & 2.20 & 60 \\
\hline 16 & Yes & Yes & 3.9 & 1 & 2 & 3.57 & 37 \\
\hline 17 & No & No & 5.2 & 1 & 2 & 3.40 & 52 \\
\hline 18 & No & No & 2.1 & 1 & 1 & 5.49 & 36 \\
\hline 19 & Yes & Yes & 6.2 & 1 & 2 & 2.99 & 59 \\
\hline 20 & No & Yes & 3.0 & 2 & 1 & 3.57 & 50 \\
\hline 21 & No & No & 2.5 & 1 & 3 & 2.64 & 44 \\
\hline
\end{tabular}

SIEV: superficial inferior epigastric vein; DIEA: deep inferior epigastric artery

Table 3: Statistical analysis of variables between groups

\begin{tabular}{lcccc}
\hline Variables & $\begin{array}{c}\text { Cases } \\
(\boldsymbol{n}=\mathbf{7})\end{array}$ & $\begin{array}{c}\text { Controls } \\
(\boldsymbol{n}=\mathbf{2 1})\end{array}$ & $\begin{array}{c}\text { Significance } \\
(\boldsymbol{P})\end{array}$ & Difference and 95\% Cl \\
\hline Diameter of SIEV $(\mathrm{mm})$, mean \pm SE & $3.04 \pm 0.63$ & $3.08 \pm 1.22$ & 0.915 & $-0.04(-1.04,0.95)$ \\
Branches of SIEV (2 branches), $\boldsymbol{n}(\%)$ & $3(42.86)$ & $5(23.81)$ & 0.371 & $19.05(21.90,60.00)$ \\
Perforators per flap, mean \pm SE & $1.86 \pm 0.69$ & $2.24 \pm 0.77$ & 0.255 & $-0.38(-1.05,0.29)$ \\
Subcutaneous thickness (cm), mean \pm SE & $3.56 \pm 0.90$ & $3.72 \pm 0.83$ & 0.652 & $-0.16(-0.92,-0.60)$ \\
Communication SIEV-perforators, $n(\%)$ & $4(57.14)$ & $8(38.10)$ & 0.418 & $19.05(-23.10,61.20)$ \\
Communication SIEVs midline, $n(\%)$ & $3(42.86)$ & $5(23.81)$ & 0.371 & $19.05(-21.90,60.00)$ \\
\hline
\end{tabular}

SIEV: superficial inferior epigastric vein; $\mathrm{Cl}$ : confidence interval; SE: standard error

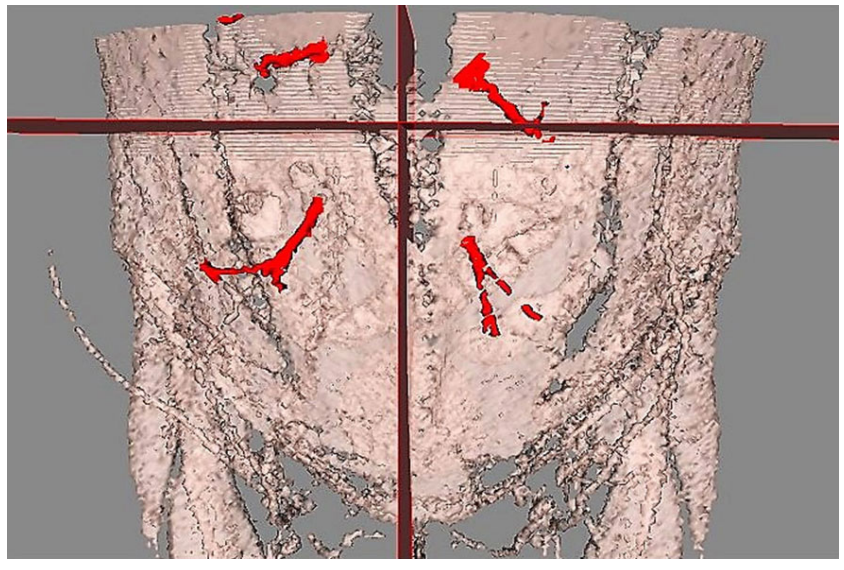

Figure 5: Three-dimensional abdominal wall reconstruction with AYRA software from computed tomography angiography images showing abdominal wall perforators diameter was not useful for predicting congestion. This finding is consistent with the present study, as no statistically significant evidence $(P=0.91)$ was found when evaluating the SIEV diameter.

Another proposed feature in studies by Schaverien et al., ${ }^{[4]}$ Rozen et al., ${ }^{[6]}$ and Blondeel et al. ${ }^{[13]}$ was the absence of direct venous communications of both SIEVs across the abdominal midline, that could favor congestion further this line. This hypothesis was not consistent with the results of our study, as no statistically significant evidence $(P=0.37)$ was found for this variable, being these communications more numerous in the case group than in the control group (48.86\% vs. $23.81 \%)$.

Taking into account the redirection of the venous 

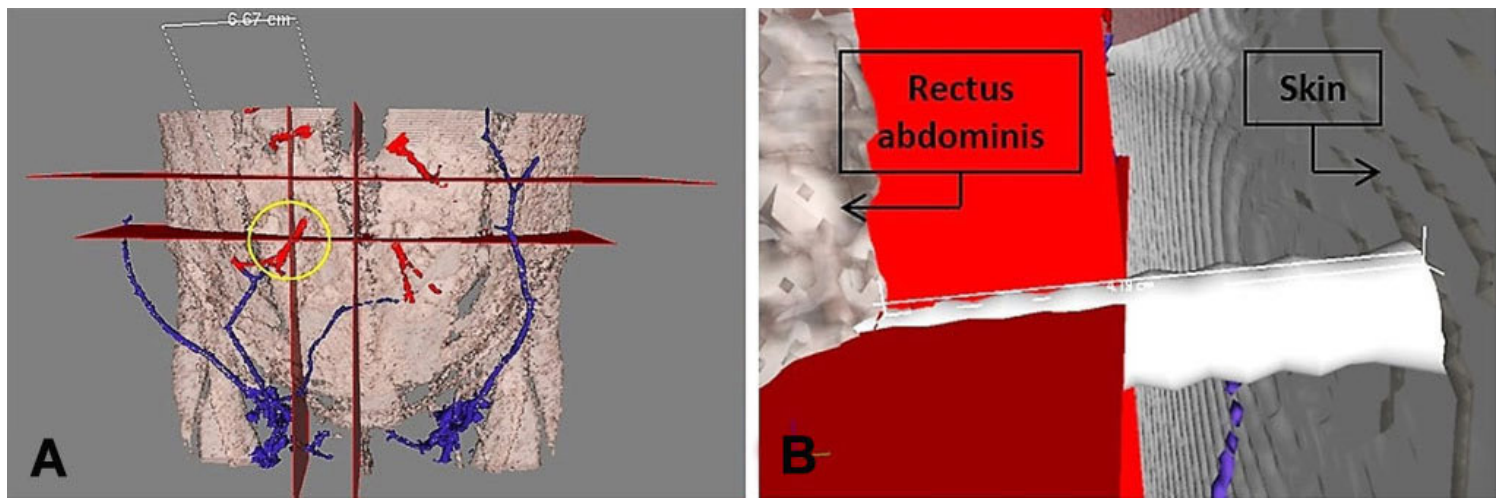

Figure 6: Three-dimensional abdominal wall reconstruction with AYRA software from computed tomography angiography images. (A) Point of measurement (circle) of flap subcutaneous tissue thickness, at the level of the iliac crests horizontally and at the midpoint of rectus abdominis width vertically; (B) measurement of flap subcutaneous tissue thickness

outflow from the superficial towards the deep system, several studies ${ }^{[6,7,11]}$ have suggested that the absence of direct communications between the SIEV and the DIEV through venous perforators could favor congestion. However, statistically significant evidence was only reported by Schaverien et al. ${ }^{[7]}$ using magnetic angioresonance, and only when a DIEP flap was dissected based on just one perforator without direct SIEV-DIEV communication. In fact, a larger proportion of these communications was found in the case group than in the control group $(57.14 \%$ vs. $38.10 \%)$ in the present study, although statistically not significant $(P=0.42)$.

The number of perforators per flap is another controversial topic. Previous research has revealed that one medial row periumbilical perforator of appropriate caliber provides the best perfusion to the DIEP flap including Hartrampf's zone IV. ${ }^{[4,5]}$ Nevertheless, from the point of view of venous perfusion, DIEP flaps sometimes exhibit a diminished drainage with an increased venous pressure. Douglas et al..$^{[5]}$ suggested that just one arterial perforator could provide the optimal perfusion, stating that with two arterial perforators the filling pressure could drop, decreasing the gradient and favoring congestion. For their part, Mohan et al. ${ }^{[18]}$ found a non-significant four-fold congestion rate in DIEP flaps based on a single perforator compared to those based on multiple perforators. In the present study, no statistically significant evidence was found for the number of perforators per flap $(P=0.25)$.

The flap subcutaneous tissue thickness was another anatomical feature analyzed. Rubino et al..[19] demonstrated that bigger flaps intrinsically develop greater flow rates, and consequently, demand a higher drainage. Bast et al. ${ }^{[14]}$ found a correlation between the suprascarpal fat pad thickness and the SIEV caliber, suggesting that thicker pads may show superficial drainage dominance. However, no evidence was reported supporting this hypothesis. Statistically significant evidence was neither found in the present study.

The number of branches of the SIEV was the last anatomical feature evaluated, with a mean of 1.43 for the case group and 1.24 for the control group. Unfortunately, no statistically significant evidence was found.

DIEP breast autologous reconstruction is recognized as a reliable procedure with excellent outcomes and low donor site morbidity. ${ }^{[3]}$ Whereas success rates of over $95 \%$ have generally been reported, some flaps exhibit vascular complications and eventually fail. ${ }^{[3]}$ The major complication that may arise is the diffuse venous congestion due to drainage insufficiency, ${ }^{[6,7]}$ neither originated by venous thrombosis nor by technical failures. Finding predictive factors of congestion preoperatively would be extremely helpful for the surgeon. Using duplex ultrasonography, Figus et al. ${ }^{[20]}$ reported that the identification of the dominant venous perforator of the flap entailed high possibilities of finding an arterial perforator of adequate caliber $(93.5 \%)$, higher than the possibilities of finding a venous perforator of good caliber after the identification of the dominant arterial perforator (69.8\%). Gravvanis et al. ${ }^{[21]}$ compared two subgroups of breast reconstructions regarding vascular dissection: dominant arterial perforator-dissected versus dominant venous perforator-dissected DIEPs. A significant higher rate of venous congestion was found in the arterial perforator group. Laporta et al. ${ }^{[22]}$ and Santanelli et al. ${ }^{[23]}$ selected the type of perforators and their number for each flap depending on the diameter of the vein, and found that medial row perforators were a negative predictor for flap complications.

As previously stated, CTA is the gold standard 
technique for planning DIEP flap surgery. To our knowledge, the present study is the first to attempt to link the morphological characteristics of the abdominal wall vessels with DIEP venous congestion by CTA and 3D virtual reconstruction. Unfortunately, according to the results obtained, this method has not demonstrated clinical utility to predict venous congestion. We hypothesize that further than a single anatomical feature, a multifactorial origin leads to venous congestion. During the dissection of a DIEP flap, physiological adaptive changes can take place. The diversion of flow through different pathways or vasodilatation are among them..$^{[15]}$ Therefore, the pressure gradient between arterial perfusion and venous drainage is modified, resulting in an imbalance that may lead to venous congestion.

When a DIEP flap becomes congested, the main effective strategy for enhancing drainage outflow is the pressure relief by venous supercharging of the SIEV, whereas supercharging the second DIEV is less commonly performed. ${ }^{[24,25]}$ This salvage procedure decreases venous pressure, increases pressure gradient and overcomes the venous congestion. Adding large caliber venous anastomosis in parallel decrease the risk of venous congestion, because of the ability to provide a superior drainage. One of the most popular modalities of venous supercharging is the anastomosis of the superficial epigastric vein to the cephalic vein. Other common strategies include the anastomosis of the SIEV to a second internal mammary vein, to an internal mammary perforator, or end-to-side to one of the DIEVs of the flap. . ${ }^{[10,25,26]}$ Less popular options include the anastomosis of the SIEV to the thoracoacromial vein, to the contralateral intermammary vein (which may need a vein graft), or to the toracodorsal vein (which may prevent the use of a latissimus dorsi as a rescue surgery in case the DIEP flap fails), among others. Notwithstanding, carrying out a second venous anastomosis is timeconsuming, which represents the main drawback of this procedure, taking between 30 to $90 \mathrm{~min}$. ${ }^{[26]}$ The experience of the surgeon and the use of coupler devices may help to reduce this lapse of time. There is another potential drawback, specifically associated with the use of the cephalic vein, which is the possibility of triggering lymphedema in the upper extremity due to the impairment of the lymphatic drainage. Women who have received radiotherapy seem to be more likely to develop this phenomenon. However, the overall risk appears to be reasonably low, being able to consider the harvest of the cephalic vein a safe option. ${ }^{[25]}$

The systematic venous supercharging has been advocated to prevent the potential drainage insufficiency, after significant results experiencing less congestion. ${ }^{[26]}$ However, a recent meta-analysis has failed to demonstrate the efficacy of the SIEV supercharging to reduce the flap-related complication rate..$^{[9]}$ Whereas venous supercharging has proved its capacity to rescue DIEP flaps that exhibit congestion and would eventually experience partial or total necrosis, the debate still continues about the convenience of supercharging every flap as a preventive strategy for minimizing perfusion-related complications. ${ }^{\left[{ }^{[9]}\right.}$

The present study has some limitations that should be considered. The low incidence of this phenomenon hinders prospective randomized controlled or prospective nonrandomized trials. Although the sample size is relatively small, this is one of the largest series specifically focused on congestive DIEP flaps reported to date. Further studies are needed to clarify the congestive phenomenon. Pressure gradient is of paramount importance, and its assessment along the flap could shed light on the subject. Larger sample sizes may also led to statistically significant differences when evaluating anatomical features.

In conclusion, this study provided new information to the literature concerning the identification of the anatomical features associated with venous congestion in DIEP flaps. No statistically significant differences were found between venous congestion of the flap and the suggested and accepted predisposing anatomical features. The congestive phenomenon is probably multifactorial, not being able to aim at any of them as the single cause. CTA was a useful tool for identifying the abdominal wall anatomy and planning DIEP breast surgery, but not for preventing the possible diffuse venous congestive phenomenon of this flap preoperatively.

\section{DECLARATIONS}

\section{Authors' contributions}

Concept design, manuscript preparation, data analysis and interpretation: A. Ruiz-Moya

Data analysis and interpretation: R.A. Lopez-Garcia

Case material's provide: D. Sicilia-Castro, T. Gomez-Cia Manuscript preparation and review: P. Infante-Cossio

\section{Financial support and sponsorship None.}

\section{Conflicts of interest}

There are no conflicts of interest.

\section{Patient consent}

All patients signed informed consent to be included in the study. 


\section{Ethics approval}

The study was reviewed and approved by the Virgen del Rocio University Hospital Ethics Committee.

\section{REFERENCES}

1. Allen RJ, Treece P. Deep inferior epigastric perforator flap for breast reconstruction. Ann Plast Surg 1994;32:32-8.

2. Zhong T, McCarthy C, Min S, Zhang J, Beber B, Pusic AL, Hofer SO. Patient satisfaction and health-related quality of life after autologous tissue breast reconstruction: a prospective analysis of early postoperative outcomes. Cancer 2012;118:1701-9.

3. Lie KH, Barker AS, Ashton MW. A classification system for partial and complete DIEP flap necrosis based on a review of 17,096 DIEP flaps in 693 articles including analysis of 152 total flap failures. Plast Reconstr Surg 2013;132:1401-8.

4. Schaverien M, Saint-Cyr M, Arbique G, Brown SA. Arterial and venous anatomies of the deep inferior epigastric perforator and superficial inferior epigastric artery flaps. Plast Reconstr Surg 2008;121:1909-19.

5. Douglas HE, Wilkinson MJ, Mackay IR. Effects of perforator number and location on the total pedicle flow and perfusion of zone IV skin and fat of DIEP flaps. J Plast Reconstr Aesthet Surg 2014;67:212-8.

6. Rozen WM, Pan WR, Le Roux CM, Taylor GI, Ashton MW. The venous anatomy of the anterior abdominal wall: an anatomical and clinical study. Plast Reconstr Surg 2009;124:848-53.

7. Schaverien MV, Ludman CN, Neil-Dwyer J, Perks AG, Raurell A, Rasheed T, McCulley SJ. Relationship between venous congestion and intraflap venous anatomy in DIEP flaps using contrastenhanced magnetic resonance angiography. Plast Reconstr Surg 2010;126:385-92.

8. Sadik KW, Pasko J, Cohen A, Cacioppo J. Predictive value of SIEV caliber and superficial venous dominance in free DIEP flaps. $J$ Reconstr Microsurg 2013;29:57-62.

9. Lee KT, Mun GH. Benefits of superdrainage using SIEV in DIEP flap breast reconstruction: a systematic review and meta-analysis. Microsurgery 2017;37:75-83.

10. Sbitany H, Mirzabeigi MN, Kovach SJ, Wu LC, Serletti JM. Strategies for recognizing and managing intraoperative venous congestion in abdominally based autologous breast reconstruction. Plast Reconstr Surg 2012;129:809-15.

11. La Padula S, Hersant B, Noel W, Niddam J, Hermeziu O, Bouhassira $\mathrm{J}$, Bosc R, Meningaud JP. Use of the retrograde limb of the internal mammary vein to avoid venous congestion in DIEP flap breast reconstruction: further evidences of a reliable and time-sparing procedure. Microsurgery 2016;36:447-52.

12. Chang CC, Huang JJ, Wu CW, Craft RO, Liem AA, Shen JH, Cheng MH. A strategic approach for DIEP flap breast reconstruction in patients with a vertical midline abdominal scar. Ann Plast Surg 2014;73 Suppl 1:S6-11.

13. Blondeel PN, Arnstein M, Verstraete K, Depuydt K, Van Landuyt
KH, Monstrey SJ, Kroll SS. Venous congestion and blood flow in free transverse rectus abdominis myocutaneous and deep inferior epigastric perforator flaps. Plast Reconstr Surg 2000;106:1295-9.

14. Bast J, Pitcher AA, Small K, Otterburn DM. Suprascarpal fat pad thickness may predict venous drainage patterns in abdominal wall flap. Microsurgery 2016;36:99-103.

15. Rozen WM, Chubb D, Ashton MW, Webster HR. Mapping the vascular anatomy of free transplanted soft tissue flaps with computed tomographic angiography. Surg Radiol Anat 2012;34:301-4.

16. Pons G, Masia J, Sanchez-Porro L, Larranaga J, Clavero JA. Paramuscular perforators in dieap flap for breast reconstruction. Ann Plast Surg 2014;73:659-61.

17. Gacto-Sanchez P, Sicilia-Castro D, Gomez-Cia T, Lagares A, Collell T, Suarez C, Parra C, Leal S, Infante-Cossio P, De la Higuera JM. Computed tomographic angiography with VirSSPA three-dimensional software for perforator navigation improves perioperative outcomes in DIEP flap breast reconstruction. Plast Reconstr Surg 2010;125:24-31.

18. Mohan AT, Zhu L, Wang Z, Vijayasekaran A, Saint-Cyr M. Techniques and perforator selection in single, dominant diep flap breast reconstruction: algorithmic approach to maximize efficiency and safety. Plast Reconstr Surg 2016;138:e790-803.

19. Rubino C, Ramakrishnan V, Figus A, Bulla A, Coscia V, Cavazzuti MA. Flap size/flow rate relationship in perforator flaps and its importance in DIEAP flap drainage. J Plast Reconstr Aesthet Surg 2009;62:1666-70.

20. Figus A, Wade RG, Gorton L, Rubino C, Griffiths MG, Ramakrishnan VV. Venous perforators in DIEAP flaps: an observational anatomical study using duplex ultrasonography. J Plast Reconstr Aesth Surg 2012;6:1051-9.

21. Gravvanis A, Tsoutsos D, Papanikolaou G, Diab A, Lambropoulou P, Karakitsos D. Refining perforator selection for deep inferior epigastric perforator flap: the impact of the dominant venous perforator. Microsurgery 2014;34:169-76.

22. Laporta R, Longo B, Sorotos M, Santanelli di Pompeo F. Tips and tricks for DIEP flap breast reconstruction in patients with previous abdominal scar. Microsurgery 2017;37:282-92.

23. Santanelli F, Longo B, Cagli B, Pugliese P, Sorotos M, Paolini G. Predictive and protective factors for partial necrosis in DIEP flap breast reconstruction. Does nulliparity bias flap viability? Ann Plast Surg 2015;74:47-51.

24. Rothenberger J, Amr A, Schiefer J, Schaller HE, Rahmanian-Schwarz A. A quantitative analysis of the venous outflow of the deep inferior epigastric flap (DIEP) based on the perforator veins and the efficiency of superficial inferior epigastric vein (SIEV) supercharging. J Plast Reconstr Aesth Surg 2013;66:67-72.

25. Landin L, Bolado P, Casado-Sanchez C, Bonastre J, Garcia-Redondo M, Zharbakhsh S, Diez J, Leyva F, Casado-Perez C. Safety of salvaging impending flap congestion in breast reconstruction by venous supercharging of the cephalic vein. Ann Plast Surg 2015;74:52-6.

26. Boutros SG. Double venous system drainage in deep inferior epigastric perforator flap breast reconstruction: a single-surgeon experience. Plast Reconstr Surg 2013;131:671-6. 